\title{
CT EVALUATION OF DISEASES OF ORBIT
}

\author{
Pushpa Ranjan', Rajeev Ranjan ${ }^{2}$
}

${ }^{1}$ Senior Resident, Department of Radiology, IGIMS, Patna.

${ }^{2}$ Assistant Professor, Department of Surgery, NMCH, Sasaram.

\section{ABSTRACT}

\section{BACKGROUND}

Computerized Tomography of Orbit of thirty seven subjects formed the basis of present study. To answer pertinent clinical queries as precisely as possible, it seems an anatomically complete CT examination in axial and coronal plane constitutes the primary diagnosis approach to all orbital lesions. The study has identified the diagnostic acumen of computed tomography for orbital lesions, opening an investigative wide in this field without causing discomfort or risk to the patient of any age.

\section{KEYWORDS}

Computed Tomography, Orbit, Imaging, Orbital Tumours.

HOW TO CITE THIS ARTICLE: Ranjan P, Ranjan R. CT evaluation of diseases of orbit. J. Evolution Med. Dent. Sci. 2016;5(47):29932999, DOI: $10.14260 /$ jemds/2016/698

\section{INTRODUCTION}

Computed tomography entered the medical imaging arena in 1970s with an abruptness, which is perhaps unparalleled in the history of medical imaging. Indeed, so successful has CT become that it effectively replaced many other radiological procedure.

Major advances in diagnosis of diseases orbit has become possible, because of newer imaging modalities like CT and MRI. CT scan of orbit is an imaging method that uses X-ray to create detailed pictures of eye sockets (Orbits) and eyes (Globes).

CT has become imaging modality of choice of orbit for evaluating trauma, tumours and inflammatory lesion. Orbits are ideal for CT imaging because of large differences in attenuation coefficient of globe, muscles, nerve, vessels and retrobulbar fat. Contrast enhancement may add definition and specificity in setting of orbital tumours.(1) vascular malformations and inflammations. Strength of CT includes exquisite bony detail, speed of examinations and excellent spatial resolutions. Detection of intraocular calcification, tumour location and its extension into intracranial spaces, optic nerve involvement are readily obtained in non-invasive fashion. It allows us to discern the location, extent and configuration of lesion and its effect on adjacent structures. It allows us to comment on possible tissue mass composition. It is also possible to obtain appropriate tissue for biopsy under CT guidance and place the radioisotope in malignant tissue where treatment modalities are not effective.

Thus, the technology of CT has allowed the radiologists to diagnose the disease of orbit with an accuracy and detail, never attainable before CT era.

\section{MATERIAL AND METHOD}

The present prospective study was done in the Department of Radiodiagnosis, Darbhanga Medical College and Hospital, Laheriasarai.

Financial or Other, Competing Interest: None.

Submission 11-03-2016, Peer Review 29-04-2016,

Acceptance 05-05-2016, Published 13-06-2016.

Corresponding Author:

Dr. Pushpa Ranjan,

Room No. 6,

New MDH, IGIMS

Sheikhpura, Patna-14.

E-mail: pushpa.rajeevranjan@gmail.com

DOI: $10.14260 /$ jemds/2016/698
A total of thirty seven patients with suspected diseases of orbit were evaluated by computed tomography. Patients of all ages were included in the present study. The cases were referred by the Department of Ophthalmology of this Institute.

\section{METHOD OF DATA COLLECTION}

1. History: Detailed chronological history was obtained about development of disease, in paediatric cases antenatal and perinatal history was also included.

2. Physical Examination: Comprising systemic and local examination.

Local examination of organ was done of proptosis, signs of inflammation, visual acuity, local tumour, pupillary reflex, etc.

\section{Pathological Examination}

a. Haematological investigation - complete blood count, BT, CT, Blood Sugar, $\mathrm{T}_{3}, \mathrm{~T}_{4}$, TSH.

b. Histopathological investigation.

\section{Radiological Examination}

a. X-ray orbit.

b. CT scan of orbit.

\section{Preparation of Patient}

Informed consent is taken from patient or his attendant. If IV contrast is used, then we tell patient not to eat or drink anything 4-5 hours before the CT scan is done and also take history of allergy to IV contrast, any recent illness and systemic diseases e.g. kidney diseases, diabetes, cardiovascular disease, etc.; if present should be treated before CT scan done.

- Patient position.

- CT scan was performed keeping patient's head in supine position for axial projection with gantry and angle tilt $0^{0}$ $10^{0}$ in reference to orbitomeatal line, scanning through orbital region. At $0.5 \mathrm{~cm}$ pitch, contiguous $5 \mathrm{~mm}$ section and $3 \mathrm{~mm}$ section in area of interest was obtained. Secondly, in prone position avoiding the molar artifacts, the direct $5 \mathrm{~mm} / 3 \mathrm{~mm}$ coronal scans were done through the orbit into the sellar region.

- Contrast-Now-a-days intravenous iodinated contrast media used in CT scan is commonly non-ionic contrast include.

1. Omnipaque,

2. Ultravist, etc. 
IV contrast media injected in dose of $1-2 \mathrm{~mL} / \mathrm{kg}$ body weight before obtaining the scan.

\section{PATHOLOGY}

Foreign Bodies in Orbit: Perforating wounds make up 30$50 \%$ of all traumatic eye injuries. Many radiographic techniques have been developed to detect and localize foreign objects in penetrating eye injuries. These include standard radiography, sonography and recently CT scan and MRI.

CT scan was used to localize intraocular and periorbital foreign bodies using axial, coronal and sagittal projections (Fig. 1) and following advantages were noted.

- Minimal patient cooperation is needed.

- No contact of any equipment was with the globe causing direct pressure.

- Accuracy in detecting foreign body adjacent to scleral wall and anteriorly.

- Visualization of sclera allow accurate separation of intraocular and intraorbital foreign bodies.

Helical scanning is superior to conventional scanner in the detection of metallic foreign bodies and when coronal reformats are generated from axial helical scan.(2)

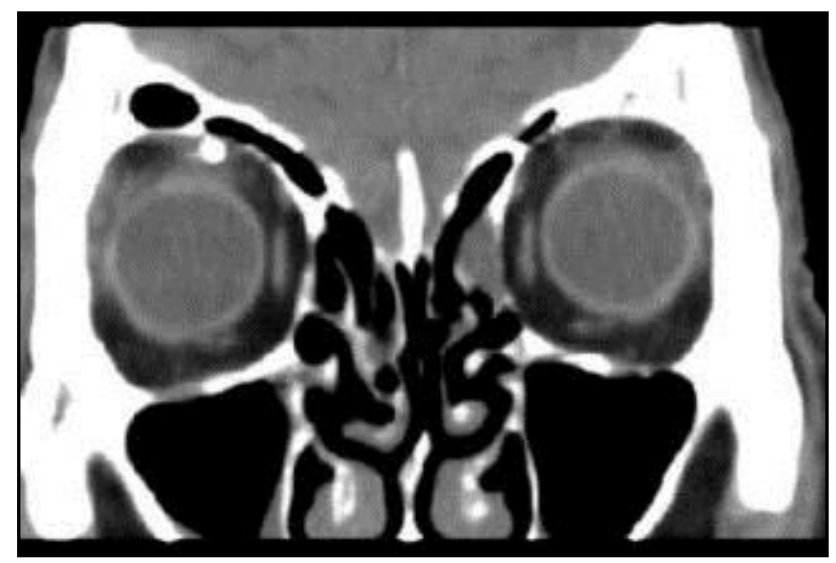

Fig. 1: Foreign Body in Orbit. Non-contrast Coronal CT Image show Small Well-Defined Hyperdense Lesion in Right Orbit above Eyeball

\section{INFLAMMATION}

Microbial cellulitis is a major cause of orbital inflammation in children and young adults. Preseptal cellulitis (Preorbital cellulitis) is infection of eyelid and surrounding skin anterior to orbital septum, caused by contiguous spread of infection from local facial and eyelid trauma, insect or animal bites, conjunctivitis. Post-septal cellulitis is infection of orbital tissue posterior to orbital septum caused by extension of infection from adjacent sinuses, especially ethmoid sinus (75-90\%). It is less common by direct infection accompanying local trauma (Eg. Insect bite, penetrating eyelid injuries) proptosis, though invariably slight should be taken as definitive evidence of postseptal involvement.

CT features of orbital cellulitis include diffuse soft tissue stranding of orbital fat with thickening of orbital structures and proptosis.(3) Advanced cases can be complicated by formation of orbital abscess which appears as fluid collection showing peripheral rim of varying thickness (Fig. 2). Small air pocket may be seen within the inflammatory process.
Subperiosteal abscess is an ophthalmic emergency, as it may cause rapid elevation of orbital pressure leading to visual impairment. On CT it appears as well-defined lentiform hypodense lesion with peripheral ring enhancement in extracoronal space adjacent to the bony orbital wall. Venous thrombosis secondary to orbital infection is common and cavernous sinus thrombosis should be suspected in case with neurological deficit or rapidly increasing proptosis.

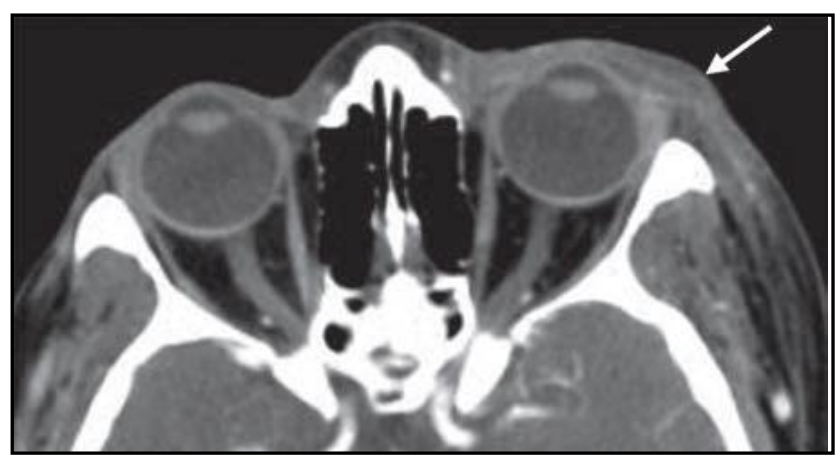

Fig. 2: Periorbital Cellulitis. Axial Contrast Enhanced CT Image Show Left Periorbital Soft Tissue Oedema without Orbital Abnormality

\section{Extraocular Muscle Lesion}

Abnormality of extraocular muscle may affect their size, shape, density characteristics on CT scanning. Thyroid ophthalmopathy and orbital myositis account for over $70 \%$ of cases. Thyroid ophthalmopathy is the commonest cause of unilateral or bilateral proptosis in adult. Most patient with thyroid eye disease are hyperthyroid, only $10 \%$ are euthyroid (Euthyroid ophthalmopathy) (Grainger $5^{\text {th }}$ edition). It affects female four or five times more than male. It presents with insidious and painless proptosis and lid lag, ophthalmoplegia and scleral injection; $85 \%$ of cases are bilateral and symmetrical (Grainger, $5^{\text {th }}$ edition).

Axial CT and MRI shows fusiform enlargement and enhancement of bellies of extraocular muscles with relative sparing of tendinous insertion (Fig. 3). This occurs in order of frequency in the inferior rectus, medial rectus, superior rectus, lateral rectus, oblique muscles, although most commonly all muscles are involved.(4) Only in $10 \%$ is there an isolated extraocular muscle involved (Grainger $5^{\text {th }}$ ed.). Importantly if an isolated lateral rectus belly enlargement is seen, cause other than thyroid ophthalmopathy (e.g. pseudotumour) should be sought.(5)

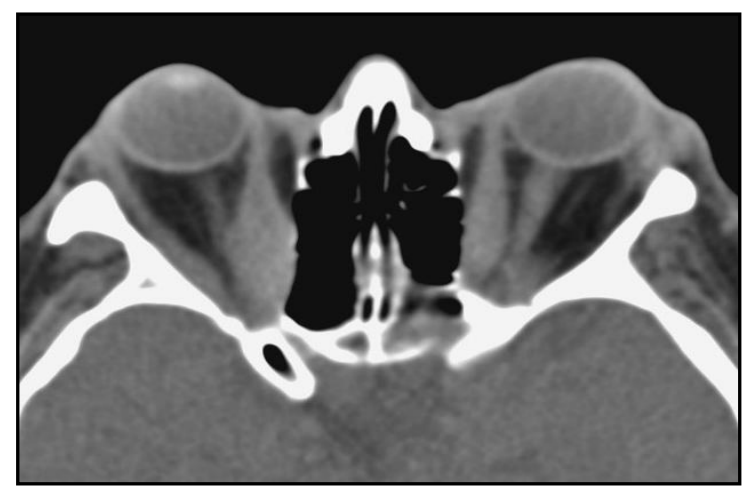

Fig. 3: Thyroid Ophthalmopathy. Axial Contrast Enhanced Image show Fusiform Enlargement and Enhancement of Belly of Medial Rectus with Sparing of Tendinous Insertion Orbital Pseudotumour 


\section{Idiopathic Orbital Inflammation}

Clinically, pseudotumour is characterized by proptosis, chemosis and impaired ocular mobility; the process being unilateral in $85 \%$ of cases and no sex or age predominance have been noted.

\section{Based on CT and US Evaluation Pseudotumours are Classified into Four Types \\ 1. Infiltrative type \\ 2. Tumefactive \\ 3. Episcleritic, and \\ 4. Myositic type.}

In their study of 20 cases, the most common forms were the infiltrative (50\%) and tumefactive (33\%).

\section{A Recent Review of the CT Features of Orbital Pseudotumours revealed \\ - Contrast enhancement $95 \%$ \\ - Infiltration of the retrobulbar fat \\ $76 \%$ \\ - Proptosis \\ - Enlargement of extraocular muscles $71 \%$ $57 \%$ \\ - Thickening of optic nerve/sheath $38 \%$}

Orbital pseudotumour were seen to occur in one of five anatomic patterns on CT scan.(6) Enhancement was seen in all of six cases given IV contrast material, but it was not useful in further defining the lesion. The diffuse, tumefactive or infiltrative type of pseudotumour fills the entire retrobulbar space and moulds itself around the globe. Even the largest of masses usually do not invade or distort the shape of the globe or erode the bone.(7)

CT appearances are categorized based on the location and extent of inflammatory process in the orbit. Though patients of all groups had broadly similar outcome, CT was valuable in identifying certain prognostic features. Pseudotumour is more likely than Grave's myositis if the tendinous insertions are also involved. Isolated lateral rectus muscle thickening favours pseudotumour, especially if lacrimal gland is also enlarged.

The Tolosa-Hunt Syndrome consists of painful ophthalmoplegia caused by cavernous sinus inflammation. CT may demonstrate asymmetric enlargement of the cavernous sinus due to an enhancing soft tissue infiltrate, which may extent through superior orbital fissure into the orbital apex.

\section{Lacrimal Gland Masses}

The overall accuracy of CT in the diagnosis of lacrimal gland was found to be $83.6 \%$.(8) CT study is useful for evaluation of posterior extension into orbital soft tissue and the presence or absence of bone destruction. ${ }^{(9)}$

Pleomorphic adenoma, benign mixed cell tumour, are welldefined homogenous soft tissue masses of deep lobe that distort the remainder of gland and may cause minor remodelling of the adjacent bony wall. Distortion of adjacent globe may be present, but is usually minor. They grow slowly and often present 1 or 2 year before patient seek clinical attention. Calcification is infrequently seen. On CT and MRI enhancement is mild and variable.(10) Malignant transformation may rarely occur.

Adenoid cystic carcinoma, most common malignancy of lacrimal gland. CT scan show poorly defined in homogeneous soft tissue mass, often with marked focal enhancement. Erosion of lateral orbital wall is seen.

\section{Neoplasm of Orbit}

Orbital Haemangioma: Benign mass composed of dilated vessel with endothelial lining lie within pre-septal or postseptal space. They are divided into capillary type and cavernous type. Both forms have female predominance.

Capillary haemangioma - most common orbital vascular tumours in infant which present at birth or shortly after. CT shows infiltrative mass of homogeneous intermediate density, which show intense contrast enhancement following contrast infusion, pooling of contrast may be seen (Fig. 4).(11)

Displacement and indentation of globe is common and there may be enlargement of affected orbit. They enlarge with Valsalva manoeuvre.

Cavernous haemangioma (Encapsulated venous malformation) - Most common vascular lesion in adult and most common primary intraconal orbital lesion. On CT homogeneous mass with dense contrast enhancement with pooling occur.

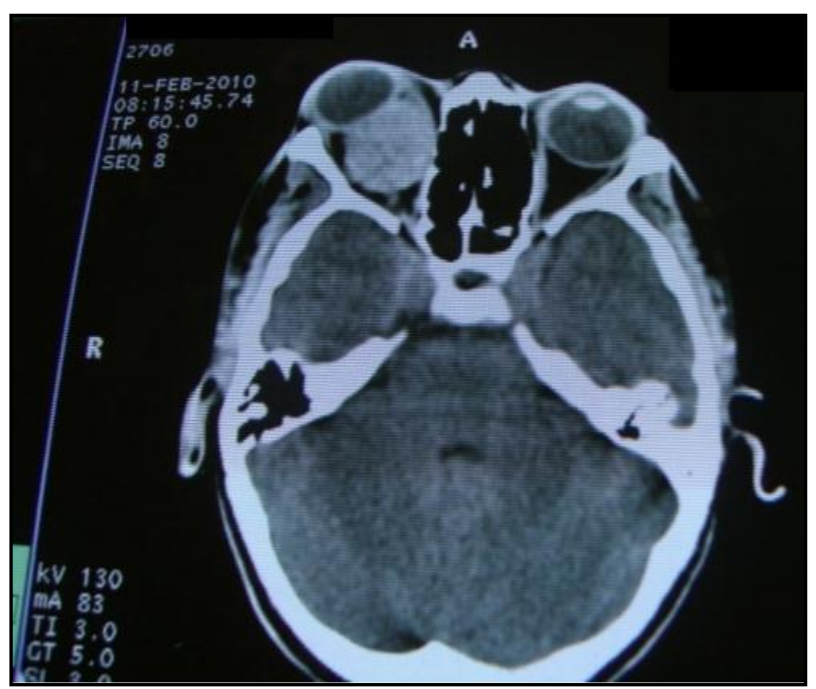

Fig. 4: Haemangioma. Axial Contrast Enhanced CT Image shows Intensely Enhanced Lesion in Right Retrobulbar Compartment which causes Proptosis of Eye

\section{Optic Nerve Glioma}

Optic nerve glioma is childhood slow growing low-grade astrocytoma with $75 \%$ of cases occurring in less than 10 years of age. CT appearance of lesion is reported as optic nerve expanded uniformly and diffusely or well-defined fusiform enlargement of optic nerve. Another characteristic feature being kinking and buckling of optic nerve.(11) Tumour enhancement is moderate-to-marked on IV contrast, but generally less than seen with meningioma. Subtle erosion and expansion of optic canal is better appreciated with CT, while MRI is better in showing intracanalicular, chiasmatic or retrochiasmatic tumour extension.(12)

\section{Optic Nerve Meningioma}

Tumour of sheath is demographically and histologically similar to those seen intracranially. CT finding of a well-defined thickening of optic nerve sheath with relative high density had been distinctive of optic nerve meningioma.

The "Tram track sign" on axial image is characteristic, but not specific of this entity. This feature is caused by central lucency is a widened optic nerve, because of enhancement of meningioma. It has 'doughnut sign' on coronal image. 
Calcification (Psammoma bodies) is common (20-25\%) (Grainger, $5^{\text {th }}$ edition).

\section{Retinoblastoma}

Is the most common intraocular malignancy in childhood. Retinoblastoma is highly malignant and may spread haematogenously via lymphatic along optic nerve. Optic nerve involvement may lead to central nervous system spread and meningeal seeding. Imaging is crucial for timely management and survival of patient with retinoblastoma. CT is investigation of choice due to dense calcification.(11) almost invariably present within retinal based soft tissue mass (Fig. 5). Only 10\% of retinoblastoma lack calcification on CT (Sutton, $7^{\text {th }}$ edition). Any calcification seen within the globe on CT in paediatric patients should be considered retinoblastoma until proven otherwise (Sutton $7^{\text {th }}$ ed.). MRI may be superior to CT in evaluation of trans-scleral or peri-nasal spread and in evaluation in pineal region.

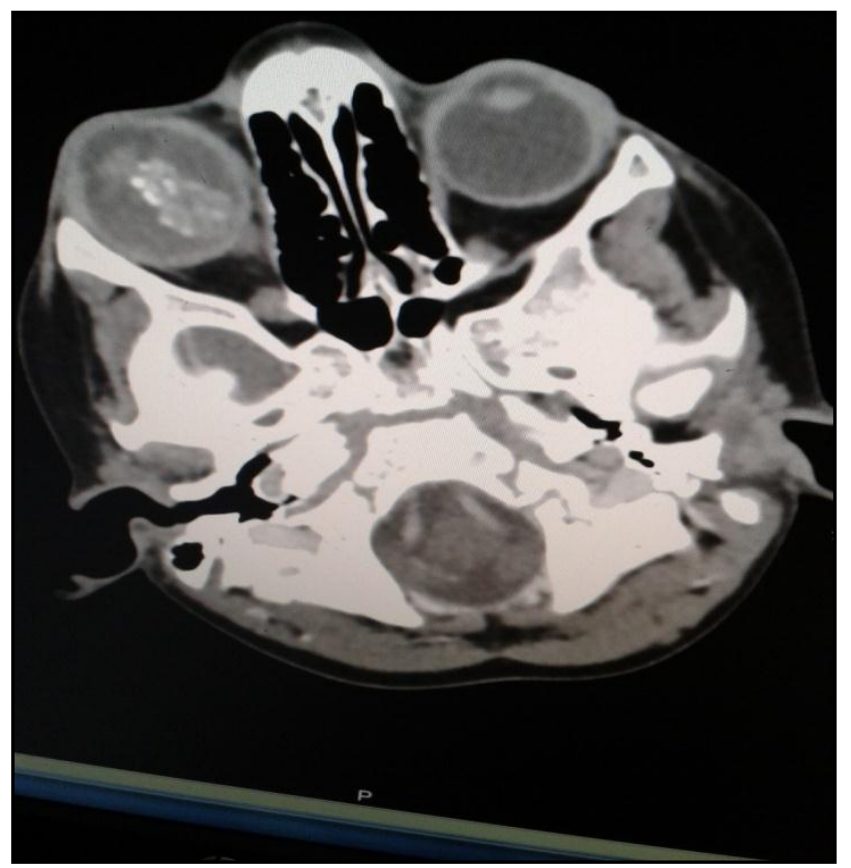

Fig. 5: Retinoblastoma. Axial Contrast Enhanced CT Image Shows Calcification in Retinal Based Soft Tissue Mass in Vitreous Chamber of Right Eye

\section{Rhabdomyosarcoma}

Most common primary orbital malignancy in paediatric age group with most patient presenting below 6 years of age. CT reveal relatively well defined soft tissue density mass (Isodense to extraocular muscles), which may involve surrounding structures.(13) The tumour may involve both the extraconal and intraconal compartment, many cause permeative bone destruction (50\%). Marked enhancement throughout the mass is seen after contrast enhancement.

\section{Neurofibroma}

Peripheral nerve tumours comprise $4 \%$ of orbital neoplasms. CT will demonstrate bony changes together with extent of the tumour, which appears as an ill-defined enhancing soft tissue mass. In addition, common abnormalities consist of widening of orbital fissures, hypoplasia of sinuses, defects of greater wing of sphenoid and roof of orbit and enlargement of the middle cranial fossa.

\section{Orbital Metastasis}

The most common primary sources in series of Heselink et al (1980) were the breast (38\%), lung (20\%) followed by $12 \%$ each of gastrointestinal and genitourinary sites. The retrobulbar metastases can involve both extraconal and intraconal spaces; they appear as masses having high absorption value and irregular margins on plain CT scans and show marked contrast enhancement. The greater wing of sphenoid is the most common site, where lesions often have soft tissue components both in the orbit and the middle cranial fossa.

\section{Miscellaneous Disorders}

Frontal bone epidermoid is an extremely rare condition. Fortunately, the specific CT scan appearance enables an accurate diagnosis to be made.

\section{OBSERVATION}

The present study "CT Evaluation of diseases of orbit" represent 37 cases of diseases of orbit in the Department of Radiodiagnosis in Darbhanga Medical College and Hospital, Laheriasarai. Efforts are made to demonstrate disease process and its component on CT images for interpretation and analysis to predict a radiological diagnosis.

\begin{tabular}{|c|c|c|}
\hline Age Range (Years) & Male & Female \\
\hline $0-9$ & 05 & 05 \\
\hline $10-19$ & 04 & 04 \\
\hline $20-29$ & 04 & 01 \\
\hline $30-39$ & 02 & 01 \\
\hline $40-49$ & 02 & 01 \\
\hline $50-59$ & 02 & 01 \\
\hline $60-69$ & 02 & 01 \\
\hline $70-79$ & 01 & 01 \\
\hline Total (\%) & $22(59.45 \%)$ & $15(40.55 \%)$ \\
\hline
\end{tabular}

Male predominance 22 male (59.45\%) with respect to 15 (40.55\%) female.

\begin{tabular}{|c|c|c|c|c|}
\hline \multirow[t]{2}{*}{ Orbital Structure } & \multicolumn{2}{|c|}{$\begin{array}{c}\text { Axial CT } \\
(n=37)\end{array}$} & \multicolumn{2}{|c|}{$\begin{array}{c}\begin{array}{c}\text { Coronal CT } \\
(n=18)\end{array} \\
\end{array}$} \\
\hline & No. & $\%$ & No. & $\%$ \\
\hline \multicolumn{5}{|c|}{ Optic Nerve } \\
\hline $\begin{array}{c}\text { Junction with } \\
\text { eyeball }\end{array}$ & 24 & 63.9 & - & - \\
\hline Anterior part & 5 & 14.7 & 1 & 3.3 \\
\hline Posterior part & 12 & 33.3 & 5 & 27.2 \\
\hline \multicolumn{5}{|c|}{ Eye Globe } \\
\hline Tunics & 12 & 33.5 & 17 & 94.6 \\
\hline Lens & 31 & 85.2 & 14 & 78.1 \\
\hline \multicolumn{5}{|c|}{$\begin{array}{ll}\text { Extraocular Muscle } \\
\end{array}$} \\
\hline Superior Rectus & 2 & 6.5 & 13 & 73.0 \\
\hline Lateral Rectus & 28 & 75.4 & 14 & 81.1 \\
\hline Medial Rectus & 28 & 75.4 & 16 & 89.2 \\
\hline Inferior Rectus & - & - & 14 & 78.4 \\
\hline Optic Canal & 32 & 86.9 & 10 & 56.7 \\
\hline $\begin{array}{r}\text { Table 2: Contrib } \\
\text { Study }\end{array}$ & $\begin{array}{l}\text { nof } A \\
\text { isea }\end{array}$ & $\begin{array}{l}\text { al and } \\
\text { of Orb }\end{array}$ & $\begin{array}{l}\text { onal } \\
=37\end{array}$ & to the \\
\hline
\end{tabular}

- Above table shows axial CT scan was done in all patients (37), but coronal CT scan was done in only 18 patients because rest of the patients were uncooperative. 
- Disease process were not confined to one structure of orbit, but involve multiple structure of orbit, e.g. neoplastic lesion especially malignant lesion involves optic nerve, eyeball, extraocular muscle (Not single, but multiple) and optic canal.

- Both lateral and radial rectus muscle were well demonstrated in axial scan; the percentage of both recti $75.4 \%$ in coronal scan former $(73 \%)$ and latter $(89.2 \%)$. Superior and inferior rectus muscles were better visualized on coronal scan, percentage ranging from $73.0 \%$ to $78.4 \%$ in present study.

\begin{tabular}{|c|c|c|}
\hline Disorder & $\begin{array}{c}\text { No. of } \\
\text { Patients }\end{array}$ & $\begin{array}{c}\text { Percentage } \\
(\%)\end{array}$ \\
\hline \multicolumn{3}{|c|}{ Injuries } \\
\hline Direct Trauma & 8 & 21.62 \\
\hline Foreign Bodies & 5 & 13.51 \\
\hline \multicolumn{3}{|c|}{ Inflammatory (Non-Specific) } \\
\hline Pseudotumours & 3 & 8.10 \\
\hline Thyroid Exophthalmos & 1 & 2.70 \\
\hline \multicolumn{3}{|c|}{ Neoplastic } \\
\hline Benign & 6 & 16.21 \\
\hline Malignant & 11 & 29.72 \\
\hline \multicolumn{3}{|c|}{ Lesion Affecting Orbital Structure } \\
\hline $\begin{array}{l}\text { Epidermoid of frontal } \\
\text { bone }\end{array}$ & 2 & 5.40 \\
\hline $\begin{array}{l}\text { Cavernous sinus } \\
\text { thrombosis }\end{array}$ & 1 & 2.70 \\
\hline $\begin{array}{r}\text { Table 3: Distri } \\
\text { Studied } t\end{array}$ & $\begin{array}{l}\text { n of Clin } \\
\text { of Orbit }\end{array}$ & terial \\
\hline
\end{tabular}

- Predominance of traumatic and neoplastic cases.

- Malignancy involve the orbit in 11 cases (29.72\%).

\begin{tabular}{|c|c|c|}
\hline Material & Intraocular & Extraocular \\
\hline Iron & 2 & - \\
\hline Lead & 1 & 1 \\
\hline Glass & - & 1 \\
\hline \multicolumn{2}{|c|}{ Table 4: Foreign Body Detection by CT (n=5) } \\
\hline
\end{tabular}

Commonest foreign material was iron.

\begin{tabular}{|c|c|c|c|c|}
\hline \multirow{2}{*}{$\begin{array}{c}\text { Age } \\
\text { Range } \\
\text { (Years) }\end{array}$} & \multicolumn{2}{|c|}{ Male } & \multicolumn{2}{|c|}{ Female } \\
\hline & Benign & Malignancy & Benign & Malignancy \\
\hline $0-9$ & 1 & 2 & 2 & 2 \\
\hline $10-19$ & - & 1 & 1 & - \\
\hline $20-29$ & - & - & 1 & - \\
\hline $30-39$ & 1 & 1 & - & - \\
\hline $40-49$ & - & 1 & - & - \\
\hline $50-59$ & - & 1 & - & 1 \\
\hline $60-69$ & - & - & - & - \\
\hline $70-79$ & - & 1 & - & 1 \\
\hline Total (\%) & $\begin{array}{c}2 \\
(11.7 \%)\end{array}$ & $7(41.17 \%)$ & $\begin{array}{c}4 \\
(23.52 \%)\end{array}$ & $4(23.52 \%)$ \\
\hline \multicolumn{5}{|c|}{$\begin{array}{c}\text { Table 5: Age and Sex Incidence of Incidence } \\
\text { of Neoplasm of Orbit ( } n=17)\end{array}$} \\
\hline
\end{tabular}

Incidence of malignancy were more in 0-20 years and 5079 years.

\begin{tabular}{|c|c|c|}
\hline Lesion & $\begin{array}{l}\text { No. of } \\
\text { Cases }\end{array}$ & $\begin{array}{c}\text { Percentage } \\
(\%)\end{array}$ \\
\hline \multicolumn{3}{|c|}{ Benign } \\
\hline Haemangioma & 1 & 5.88 \\
\hline Optic nerve glioma & 2 & 11.76 \\
\hline Optic meningioma & 1 & 5.88 \\
\hline Neurofibromatosis & 1 & 5.88 \\
\hline $\begin{array}{l}\text { Adenoma of lacrimal } \\
\text { gland }\end{array}$ & 1 & 5.88 \\
\hline \multicolumn{3}{|c|}{ Malignant } \\
\hline Osteosarcoma & 1 & 5.88 \\
\hline Rhabdomyosarcoma & 3 & 17.64 \\
\hline Neuroblastoma & 1 & 5.88 \\
\hline Carcinoma of eyelid & 1 & 5.88 \\
\hline \multicolumn{3}{|c|}{ Metastasis in Orbit } \\
\hline Retrobulbar & 3 & 17.64 \\
\hline Ocular & 1 & 5.88 \\
\hline $\begin{array}{c}\text { Invasion by Contiguous } \\
\text { Tumour }\end{array}$ & 1 & 5.88 \\
\hline \multicolumn{3}{|c|}{ Table 6: Prevalence of Neoplasm of Orbit $(n=17)$} \\
\hline
\end{tabular}

Further classification of orbital tumour showed that there were 6 primary tumours and 4 metastatic tumours from primary from lung (02) one each from breast and thyroid out of 17 cases.

\section{DISCUSSION}

Thirty seven cases of diseases of orbit constituted the present study with reference to CT analysis of orbit in perspective of anatomic localization, pathologic process and the extent demonstrate as diagnostic approach.

The range of disease process involving orbit are best demonstrated by CT in form of both soft tissue and osseous detail in axial and coronal projection.

Disease process were not confined to one structure of orbit, but involve multiple structure of orbit, e.g. neoplastic lesion especially malignant lesion involves optic nerve, eyeball, extraocular muscles (Not single muscle, but multiple) and optic canal [Table 2].

Junction of optic nerve with the globe is best seen in axial scans, whereas tunics of eyeball is equally well outlined in both projections. Extraocular muscles namely superior (73.0\%) and inferior $(78.4 \%)$, recti were better visualized adjacent to roof and floor of orbit respectively in coronal scans. Lateral rectus $(75.4 \%)$ and medial rectus $(75.4 \%)$ in axial section and in coronal sections, the former $(81.1 \%)$ and latter $(89.2 \%)$ were demonstrated in present study. Optic canal (On disease side) was more precisely visualized in axial CT technique. In present study, it was $86.9 \%$.

Density measurement are more reliable on coronal CT scan due to elimination of the partial volume effect, which has a detrimental influence on axial CT of orbits.

Use of intravenous contrast material was helpful, but not essential for intraorbital tumour diagnosis with late generation technique. In their study, approximately one-fourth of the cases did not receive contrast medium and there were no false negative finding in that group. Nevertheless, contrast enhancement aid in characterizing some lesions, particularly varices, small angiomas and sheath meningiomas.

It is probably not necessary to obtain initial non-contrast scans in all cases. Most of the time, it is sufficient to detect the differential enhancement between adjacent structures on the contrast. 
Any contrast present may become equivocally observed at wide window setting, giving the viewer a virtual non-contrast scan. The lower the number the more sensitive the CT is in detecting small degree of contrast enhancement; however, the grainer will be the image. CT accurately localized the foreign bodies in all 5 cases under this study.

Male predominance, young age, injury by flying metallic particle (Lead pellet - 2 and iron fragments - 2) observed in present study [Table 4].

CT is clearly superior to conventional radiography in demonstrating the precise anatomic location of foreign bodies within the globe and their sequelae in patient who may be difficult to examine clinically.

All the three cases of pseudotumour showed proptosis and two cases (66.6\%) showed extraocular muscle enlargement. Optic nerve sheath enlargement, infiltration of retrobulbar fat were present in equal incidence (33.3\%), especially in infiltrative type of orbital pseudotumour.

There were two diffuse and one myositic type of pseudotumour. No episcleritis type was noted in the present study.

In the absence of clinical information, acute and chronic orbital pseudotumour are difficult to be differentiated by CT unless follow-up scan are obtained.

Male predominance was shown incidence of malignancy were more in 0-9 years and 50-59 years' age group.

There were $6(35.28 \%)$ primary malignant tumours and 4 (23.64\%) metastatic tumours out of 17 cases. There were 3 (17.64\%) cases of rhabdomyosarcoma, 1 (5.88\%) case of osteosarcoma. Among optic nerve neoplasm, 2 (11.76\%) case of optic nerve glioma and 1 (5.88\%) case of optic nerve sheath meningioma were noted. Haemangioma, neurofibroma, adenoma of lacrimal gland is shown in 1 (5.88\%) case respectively. Invasion of orbit by contiguous lesion shown in one lesion [Table 6].

The present study showed solitary lesion of haemangiomas in right orbit, in a male infant of 8 months of age, exhibited a mass of increased attenuation on pre-contrast CT as well as intense enhancement after intravenous injection of iodinated contrast. No internal calcification was detected.

Among two cases, one case of optic glioma shown in tenyear-old child with decreasing visual acuity of left eye (Without proptosis) was examined by CT and contiguous axial sections showed thickening and enlargement of left optic were near orbital apex. Another case was present in seven-year-old female, optic nerve glioma are uncommon tumour of the orbit (1 in 100,000 eye complaints) that generally occur in $1^{\text {st }}$ decade of life.

Primary orbital meningioma usually arises from the optic nerve sheath, occurring most commonly in middle age women. But in our study case of meningioma seen in 34 year male patient manifested as large retrobulbar mass of well-defined margin and widening of left optic canal. Resection biopsy postoperatively shown it as a transitional meningioma. On CT optic nerve sheath meningioma is most effectively demonstrated with thin axial section, usually shown as smooth fusiform soft tissue lesion surrounding the optic nerve.(1)

Neurofibromatosis presenting as orbito-fascial disfigurement was noted in 14 years old patient. CT demonstrated buphthalmos, dysplasia of greater wing of sphenoid and ill-defined soft tissue mass in orbit.
The most common sign of orbital rhabdomyosarcoma is a rapidly evolving exophthalmos. It is the most common primary malignant tumours of childhood.(13) Out of three cases $(17.64 \%)$ of rhabdomyosarcoma, the youngest patient at time of presentation was 11-month-old female infant.

Recurrence of rhabdomyosarcoma was noted in 6 years old male, whose eye was enucleated back for this malignancy.

Rhabdomyosarcoma appear as an enhancing isodense mass, which may infiltrate the retrobulbar tissue and muscle planes, often involving the posterior aspect of globe. Most orbital rhabdomyosarcomas are the embryonal type, which occur in children appear in the soft tissue of the orbit and are not associated with extraocular muscles. These sarcomas may arise in the paranasal region and invade the orbit or may originate in extraocular muscle and affect the adjacent sinuses.

Other less common orbital tumours include osteogenic sarcomas, carcinoma of eyelid and primary intraorbital neuroblastoma. The present study has one case $(5.88 \%)$ of osteosarcoma originating from lateral wall of the left orbit. The soft tissue component showed heterogenous infiltration of the tumour (Intraorbital plus intracranial), total extent was defined in both the CT sections studied together.

Four instance of metastatic deposit in orbit (2 from lung, 1 each from breast and thyroid) have been noted in present study. Metastases to the orbit most often has indistinct boundaries and are diffusely infiltrating and at times may have an appearance similar to that seen with extensive pseudotumour.

Clinical course in orbital metastatic disease include abrupt onset of proptosis. CT study at a later date demonstrated enlarging mass lesion in orbit infiltrating the adjacent sphenoid wing and involvement of dura. In general, the CT findings are not specific for the histology of metastatic tumour and the diagnosis is often aided by knowledge of the extent of primary malignant tumour.

The 17 neoplastic lesion were mostly posterior (52.9\%) and myositic (23.5\%) in location. All 3 pseudotumour were posterior with $66 \%$ of cases being diffuse and $94 \%$ of cases being myositic. There was one case of thyroid ophthalmopathy with posterior involvement.

\section{SUMMARY AND CONCLUSION}

Computerized Tomography of Orbit of thirty seven subjects formed the basis of present study. To answer pertinent clinical queries as precisely as possible, it seems an anatomically complete CT examination in axial and coronal plane constitutes the primary diagnosis approach to all orbital lesions.

CT offers the advantage of imaging the globe, when inaccessible to direct ophthalmologic viewing. Metallic foreign bodies in 5 cases were precisely located in relation to structures in the orbit. Lead pellets usually cause streak artifacts in CT image, but this does not detract significantly the valuable soft tissue and bony information available.

The pathomorphological signs have been demonstrated as far as possible in idiopathic orbital inflammation (3 cases). However, no specific CT findings were established in diagnosis of pseudotumour with absolute certainty.

The location and extent of a neoplasm in the orbital region may be determined in all cases, but it is seldom possible to identify the exact nature of the lesion. Whereas haemangioma could easily be differentiated due to its characteristic 
appearance, a differential diagnosis between optic glioma, meningioma and neuroblastoma could not be depicted by CT alone.(14)

Malignant entity of osteosarcoma (One case) and rhabdomyosarcoma (Three cases) and metastases (From lung2 , breast-1, thyroid-1) invariably showed partial destruction of osseous contour of the orbit. Solitary instance of carcinoma breast's secondary in choroids layer of eyeball had been a rare CT feature.

In order to obtain additional information out of density measurement in different orbital tumours, the Hounsfield units do not reveal typical diagnostic criteria either before or after contrast enhancement. Incidentally, benign tumours may have similar density as of malignant lesions; nevertheless, the advantage of contrast-enhanced CT lines in improved tumour visualization, specially its extraorbital component.(15)

Our review envisages the need of sheet anchor clinical background to supplement a CT study. Only with such approach can a secure differential diagnosis be offered and more importantly the CT evaluation is tailored to shell out imperative pathomorphologic details of interpretation.

The study has identified the diagnostic acumen of Computed Tomography for orbital lesions, opening an investigative wide in this field without causing discomfort or risk to the patient of any age.

\section{REFERENCES}

1. Kia AB, Naheed MH, Elias DA, et al. Optic nerve tumour: role of MRI and CT. Radiol Clin North Am 1987;25(3):561-81.

2. Herman M, Valkova Z. Intraorbital wood foreign bodies. Radiology 1993;188:878.

3. Handler LC, Davey IC, Hill JC, et al. The acute orbit: differentiation of orbital cellulitis from subperiosteal abscess by CT. Neuroradiology 1991;33(1):15-8.
4. Sabharbav KK, Chouhan AL, Jain S. CT evaluation of proptosis. Indian Jour Of Radiol 2006;16(4):683-8.

5. Basu S, Nair N, Arvind N. Unilateral proptosis with thyrotoxicosis resulting from solitary retro -orbital soft tissue metastasis from follicular ca thyroid. Clin Nucl Med 2001;26(2):136-8.

6. Atlas SW, Grossman RI, Savino PJ, et al. Surface-coil mr of orbital pseudotumour. AJNR 1987;8:141-6.

7. Alvord EC, Lofton S. Gliomas of the optic nerve or chiasm. outcome by patients age, tumours site and treatment. J Neurosurg 1988;68(1):85-98.

8. Heran F. Imaging of orbital masses. Nuerochirurgie 2010;56(2-3):89-120.

9. Mauriello JA, Lee HJ, Nguyen L. CT of soft tissue injury and orbital fracture. Radio clin North Am 1999;37(1):241-52.

10. Bloching $H$, Beck $R$, Knipping $S$, et al. Orbital space occupying lesion practical aspects of imaging. HNO 2001;49(1):21-8.

11. Kandpal H, Vashisht $S$, Sharha R, et al. Image specimen of paediatric orbital pathology: a pictorial review. IJO Indian Journal of Ophthalmology 2006;54(4):227-236.

12. Hopper KD, Sherman JL, Boar DK, et al. CT and MRI imaging of the paediatric orbit. Radiographics 1992;12(3):485-503.

13. Mafee MF, Pai E, Philip B. Rhabdomyosarcoma of orbit. Evaluation with MRI and CT. Radiol Clin North Am 1998;36(6):1215-27.

14. Hollander MD, Patrick FM, O'Connor SG, et al. Optic gliomas. Radiol Clin North Am 1999;37(1):59-71.

15. Naik MN, Tourani KL, Shekhar CG, et al. Interpretation of CT imaging of eye and orbit a systematic approach. IJO Indian Journal of Ophthalmology 2002;50(4):339-353. 